\title{
Obrigatoriedade e gratuidade da educação nos Estados Parte do Mercosul
}

\author{
Compulsory and gratuitous schooling in the
}

Mercosur Member States

\section{Carlos Antônio Diniz Júnior ${ }^{1}$}

\section{Resumo}

O objetivo deste artigo é analisar os ordenamentos normativos associados à obrigatoriedade e à gratuidade da educação nos Estados Parte do Mercosul. Alicerçado em referenciais teóricos que discutem a temática e tendo por base a análise documental, o artigo examina a constituição nacional, a lei geral da educação e demais ordenamentos que regulamentam a obrigatoriedade e a gratuidade. Entre seus resultados, revela que declarações e demais documentos editados por organismos internacionais contribuíram para tal normatização no âmbito de cada país. Demonstra ainda que, no caso do Mercosul, a educação é considerada elemento importante para o desenvolvimento e a integração da região. Entretanto, embora o trabalho identifique avanços no que diz respeito à regulamentação da ampliação da escolarização, tais documentos não foram suficientes para garantir a efetividade do acesso dos sujeitos em idade escolar.

Palavras chave: Escolaridade obrigatória; gratuidade; MERCOSUL.

\footnotetext{
${ }^{1}$ Mestre e doutorando em Educação pela Universidade Federal do Estado do Rio de Janeiro. Bolsista CAPES. Professor na Escola de Formação de Professores do Centro Universitário Celso Lisboa - RJ. Email: junior.diniz.jd@gmail.com
} 


\begin{abstract}
This paper aims to analyze the normative orders associated with compulsory and free education in the Mercosur States Parties. Based on theoretical references that discuss the theme and based on documentary analysis, the paper examines the national constitution, the general education law and other regulations that regulate mandatory and gratuity. Among its results, it reveals that declarations and other documents edited by international organizations contributed to such standardization within each country. It also demonstrates that, in the case of Mercosur, education is considered an important element for the development and integration of the region. However, we identify advances regarding the regulation of the expansion of schooling, such documents were not sufficient to ensure the effective access of school-aged subjects.
\end{abstract}

Keywords: Compulsory education; gratuity; MERCOSUR.

\title{
1. Introdução
}

Este artigo objetiva apresentar e analisar os ordenamentos normativos que regulamentam a obrigatoriedade e a gratuidade da educação no âmbito dos Estados Parte do Mercosul (Argentina, 1994, 2006; Brasil, 1988; Paraguai, 1992; Uruguai, 1967). Destacamos que este estudo é resultado parcial de pesquisa de doutorado, em andamento na Universidade Federal do Estado do Rio de Janeiro (UNIRIO).

Ao levarmos em conta a organização do Estado de Direito, compreendemos que a educação precisa ser, necessariamente, normatizada através do arcabouço legal de cada país. Entendemos, contudo, que os ordenamentos normativos, por si só, não garantem a efetivação do direito à Educação (UNESCO, 2013). Nesse cenário, organismos internacionais, em especial aqueles vinculados à Organização das Nações Unidas (ONU), através de suas declarações e convenções (ONU, 1948, 1959, 1966; UNESCO, 1990, 2000, 2015), exercem um papel importante e decisivo. A própria Unesco, agência da ONU, aponta que o direito à educação está imbricado na ideia e na necessidade de se garantir a universalização do acesso à escola, por 
meio de normatizações que delimitem a escolaridade obrigatória, para que assim possam, através de políticas públicas, garanti-lo (UNESCO, 2013).

De tal modo, os tratados internacionais se consolidam como referências obrigatórias no âmbito do sistema de direitos internacionais. Além disso, o crescente processo de internacionalização dos direitos está diretamente relacionado à pungente necessidade de se construir soluções para problemas que não se restringem mais à ordem de um Estado, mas afetam, de maneira profunda e crucial, a esfera regional e/ou global (Souza, 2017).

Tal constatação aponta que os Estados signatários desses ordenamentos devem assumir a responsabilidade de promover (e garantir) tais direitos aos seus cidadãos. Ao pensarmos nesse processo, é fundamental compreender que os organismos internacionais passam a ter papel fundamental na dinâmica do escopo legal de cada país, ainda que, em alguns casos, decisões não sejam necessariamente internalizadas no direito doméstico de cada nação, tendo, portanto, papel de sugerir políticas e práticas aos países signatários e que ratificaram tais normas internacionais.

Nesse contexto, a educação ganha um papel de destaque no âmbito do Mercosul, uma vez que, em consonância com orientações da Comissão Econômica para a América Latina e Caribe (CEPAL), é evocada como um elemento que contribui para os processos de integração e para o necessário desenvolvimento da região (CEPAL, 1994). De tal modo, no âmbito do Mercosul2 , foi instituído o Mercosul Educacional, com a missão de instituir um espaço educacional comum através da coordenação de políticas que visassem a inclusão da educação no processo de integração.

Assim, a normatização da obrigatoriedade e da gratuidade da educação é o foco central da análise deste artigo.

\footnotetext{
2 Mercado Comum do Sul (Mercosul), instituído em é uma estratégia de integração, objetivando a conformação de um mercado comum, tendo como Estados Parte, quando da sua criação, a Argentina, o Brasil, o Paraguai e o Uruguai.
} 


\section{Enquadramento teórico}

O direito à educação, no cenário internacional, tem como marco alguns dos principais ordenamentos normativos que visam a consolidar o acesso à escolarização. Souza (2017) sinaliza os principais documentos, no âmbito internacional, que objetivam impulsionar o acesso à educação básica nos países. $\mathrm{A}$ articulação do direito internacional à educação com os ordenamentos normativos editados pelos Estados fortalece a dinâmica de proteção dos direitos fundamentais. Nesse sentido, assegurar a educação como direito humano, inalienável, aponta que o país está em consonância com a perspectiva do desenvolvimento integral, numa lógica de garantia da cidadania (Piovesan, 2005).

No que tange à educação, o direito internacional desempenha o importante papel de determinar aos países os princípios básicos e as garantias em relação a esse direito social, de modo que estes estabelecem ordenamentos normativos domésticos, em consonância com as determinações internacionais, para regulamentarem suas políticas. Documentos editados pela ONU $(1948,1959,1966)$ e pela UNESCO $(1990,2000,2015)$ contribuíram nesse processo e, ainda, avançaram no que diz respeito à compreensão do que é o direito à educação e de sua ampliação. Se nos primeiros documentos - ONU $(1948,1959,1966)$ - o foco estava em reforçar o direito humano à educação e em buscar garantir o acesso à escola. Ao longo dos anos, os demais ordenamentos - UNESCO (1990, 2000, 2015) - passaram reforçar a necessidade de uma oferta de qualidade e com equidade.

Para Rabelo et al. (2009), os documentos editados pela Unesco na década de 1990 e no ano 2000, frutos de conferências internacionais de educação, apresentam um elemento em comum. Além de pautarem o tema da educação, trazem à cena a significativa participação de organizações não governamentais (ONGs) no processo de discussão dos rumos das políticas educacionais. Nessa articulação, prazos e metas foram definidos, nos quais os países signatários, por meio dos compromissos firmados, assumiram a responsabilidade no seu alcance.

Tais ordenamentos são determinados por seu papel no âmbito do direito internacional. Para Ventura e Seitenfus (1995), esse direito está relacionado a uma tríplice função: 1. repartição de competência entre os estados soberanos, cada qual 
com sua delimitação territorial, ao qual exerce sua jurisdição; 2. fixação das obrigações dos Estados-Nação de modo que as suas liberdades de atuação são (de)limitadas, e; 3. regulamentação das relações entre as organizações internacionais.

Nesse sentido, a educação passa a ser considerada um direito dos sujeitos e o processo de escolarização vai ganhando maior robustez, seja no sentido de ampliar o acesso, como também no aumento dos anos de escolaridade obrigatória. Essa expansão traz ainda a necessidade de se garantir esse acesso através da gratuidade, sendo este o papel do Estado. Os referidos documentos não determinam que essa oferta se dê, necessariamente, nos sistemas públicos de educação, mas que o Estado possa garantir esse direito, inclusive através de articulação com o setor privado, desde que garantida a gratuidade à população.

Tal fator oportuniza que sejam colocadas em prática políticas de voucher-a exemplo do que ocorre no Chile - nas quais o Estado repassa recurso para escolas particulares parceiras, denominadas subvencionadas, para o atendimento aos estudantes (Bellei, 2005) e cumprir o que está disposto na legislação sobre a obrigatoriedade e a gratuidade da educação.

Afora a necessidade de se ampliar a escolarização, determinada em documentos de organismos internacionais (ONU, 1948, 1959, 1966; UNESCO, 1990, 2000, 2015), a educação também é compreendida como um vetor de desenvolvimento de países e de regiões (CEPAL, 1994). Sob essa perspectiva, o Mercosul instituiu, através da Decisão 07/1991, o setor educacional do Mercosul, chamado de "Mercosul Educacional", com a missão de constituir um espaço educacional comum através da coordenação de políticas que visem à inclusão da educação no processo de integração do Mercosul (MERCOSUL, 1991).

O referido setor não se sobrepõe à soberania dos países em relação às políticas educacionais, se consolidando mais como um espaço para a confluência de ideias que poderão influenciar políticas domésticas no âmbito de cada nação. No âmbito do Mercosul, é importante destacar que as constituições e outros ordenamentos normativos dos países bloco já apontavam para a garantia de um 
nível mínimo de escolarização para o indivíduo, reiterando-o como um direito diretamente relacionado ao exercício da cidadania (Souza, 2017).

\section{Metodologia}

Optamos pela pesquisa de abordagem qualitativa, por sua contribuição na compreensão em profundidade dos "fenômenos educativos e sociais, à transformação de práticas e cenários socioeducativos, à tomada de decisões e também ao descobrimento e desenvolvimento de um corpo organizado de conhecimentos" (Esteban, 2010, p. 127).

Realizamos ainda uma pesquisa documental, considerando que os documentos serão a fonte primária dessa pesquisa e ainda, por representarem uma importante fonte de pesquisa, na qual é possível contribuir com as análises do pesquisador (Lüdke; André, 2013). Os documentos do vinculados aos organismos internacionais (ONU, 1948, 1959, 1966; UNESCO, 1990, 2000, 2015) e os ordenamentos normativos que tratam da obrigatoriedade e gratuidade da escolarização nos Estados Parte do Mercosul (Argentina, 1994, 2006; Brasil, 1988; Paraguai, 1992; Uruguai, 1967) foram coletados nos sites oficiais dos respectivos organismos e países analisados. Posteriormente, tais documentos foram minuciosamente analisados, buscando identificar os elementos propostos neste estudo.

Para contribuir no processo de investigação, optamos pela referência do estudo comparado para a condução da pesquisa. Ainda que os países possuam realidades distintas, os processos externos - ligados ao contexto da globalização influenciam as suas políticas domésticas, seja pela necessidade de se colocar ou de se manter no fluxo da economia global (Ferrer, 2002). Nesse sentido, destacamos que o estudo comparado em educação contribui para o desvelamento do "sucesso e do fracasso de uma mesma política em realidades distintas" (Corrêa, 2011, p. 267), bem como para a "quebra de fronteiras no campo da produção do conhecimento" (Nóvoa, 2009, p. 26). Para Trojan (2009), o estudo comparado não se limita a um aspecto classificatório, mas contribui para a análise do distanciamento e da aproximação entre realidades. 
Um estudo comparativo pode ser destacado por sua relevância ao possibilitar a relação entre as políticas domésticas e as tendências globais, o que possibilita que a educação comparada atravesse "as fronteiras dos diferentes países" (Nóvoa, 1994, p. 105). Compreendemos que se trata de uma articulação para convergência de ideias e orientações que podem influenciar as decisões de cada Estado que compõe o setor. Sendo assim, destacamos que os sistemas educacionais em todo o mundo variam significativamente em termos de estrutura, conteúdo curricular e, em especial, no que diz respeito aos processos históricos de constituição daquela nação. Portanto, há um grande - e necessário - desafio de compará-los ou medir o progresso em direção às metas nacionais e internacionais.

\section{Apresentação/discussão dos resultados}

Cabe destacar que a análise das constituições nacionais dos países do Mercosul é delicada e pode apresentar algumas limitações, uma vez que existem diversas formas de organização do Estado na região. Nesse sentido, para viabilizar a análise comparada dos países em questão, serão analisados dois elementos, que assumem importância no que diz respeito à oferta da educação aos cidadãos, quais sejam: a gratuidade e a obrigatoriedade. No que tange à gratuidade, a Campanha Latino-Americana pelo Direito à Educação (CLADE) aponta que esse princípio está estabelecido em todas as Leis Gerais de Educação, com exceção da Colômbia (CLADE, 2014, 2015). De acordo com Groso e Magalhães (2016), o Estado deve institucionalizar mecanismos para garantia desse direito, bem como de reparação à sua violação.

\subsection{0 que dizem os ordenamentos normativos}

O Tabela 1 aponta que todos os países do Mercosul estabelecem o princípio de gratuidade da educação em suas constituições. 


Tabela 1. Ordenamento Normativo que regulamenta a gratuidade e a
obrigatoriedade da escolaridade nos Estados Parte do Mercosul
\begin{tabular}{|l|l|l|}
\hline País & Obrigatoriedade & Gratuidade \\
\hline Argentina & Lei n. 26.206/2006 (Art. 16) & $\begin{array}{l}\text { Constituição Nacional } \\
\text { Argentina/1994 (Art. 75) }\end{array}$ \\
\hline Brasil & $\begin{array}{l}\text { Constituição da República } \\
\text { Federativa do Brasil/1988 } \\
\text { (Art. 208) }\end{array}$ & $\begin{array}{l}\text { Constituição da República } \\
\text { Federativa do Brasil/1988 } \\
\text { (Art. 206 e Art. 208) }\end{array}$ \\
\hline Paraguai & $\begin{array}{l}\text { Constitución Nacional de la } \\
\text { República del } \\
\text { Paraguay/1992 (Art 76) }\end{array}$ & $\begin{array}{l}\text { Constitución Nacional de la } \\
\text { República del Paraguay/1992 } \\
\text { (Art. 76) }\end{array}$ \\
\hline Uruguai & $\begin{array}{l}\text { Constitución de la Republica } \\
\text { Oriental del Uruguay/1967 } \\
\text { (Art 70) }\end{array}$ & $\begin{array}{l}\text { Constitución de la Republica } \\
\text { Oriental del Uruguay/1967 } \\
\text { (Art. 71) }\end{array}$ \\
\hline
\end{tabular}

Fonte: Elaboração própria com base em Argentina (1994, 2006), Brasil (1988), Paraguai (1992) e Uruguai (1967).

A Constituição Nacional Argentina estabelece os princípios de gratuidade (e equidade) da educação pública estatal por meio do Art. 75. É importante destacar que o referido trata das atribuições do Congresso e não especificamente da educação. Sinalizamos que, além de estar garantido no artigo 75 (Argentina, 1994), e a Ley de Educación Nacional (Argentina, 2006) reitera tal princípio.

Já a obrigatoriedade está inscrita na Lei de Educação Nacional (Argentina, 2006), que determina "la obligatoriedad escolar en todo el país se extiende desde la edad de cinco (5) años hasta la finalización del nivel de la Educación Secundaria" (Argentina, 2006, Art. 16). Para Alesso (2016), a promulgação de uma nova lei da educação na Argentina avançou significativamente a pauta educacional, pois, além de assegurar o direito à educação, ampliou os anos de escolaridade obrigatória, uma vez que inclui a obrigatoriedade às crianças de 05 anos e os anos de escolaridade vinculados à escolaridade obrigatória.

Artículo 75. - Corresponde al Congreso:

19.- [...] Sancionar leyes de organización y de base de la educación que consoliden la unidad nacional respetando las particularidades provinciales y locales: que aseguren la responsabilidad indelegable del Estado, la participación de la familia y la sociedad, la promoción de los valores democráticos y la igualdad de oportunidades y posibilidades sin discriminación alguna; y que garanticen los principios de gratuidad y equidad 
de la educación pública estatal y la autonomía y autarquía de las universidades nacionales. Dictar leyes que protejan la identidad y pluralidad cultural, la libre creación y circulación de las obras del autor; el patrimonio artístico y los espacios culturales y audiovisuales (Argentina, 1994, Art. 75 grifos nossos).

A referida lei determina que o tempo de escolaridade se estende desde os cinco anos de idade até os 17 anos, totalizando 13 anos. A educação básica argentina, que é composta: 1. pela educação inicial, que atende as crianças de 45 dias até os cinco anos de idade - sendo este último obrigatório; 2. pela educação primária ${ }^{3}$, destinada à formação das crianças a partir dos seis anos de idade, e; 3. pelo ensino secundário, destinado aos adolescentes e jovens, sendo organizado em dois ciclos, com três anos de escolaridade cada um (Argentina, 2006). No ano de 2014, a Ley no 27.045, de 03 de dezembro de 2014, declarou "obligatoria la educación inicial para niños/as de cuatro (4) años en el sistema educativo nacional' (Argentina, 2014, Art. 1), ampliando assim a escolaridade obrigatória no país.

No que diz respeito ao Brasil, a gratuidade e a obrigatoriedade estão determinadas no mesmo artigo da Constituição Federal, que determina: "O dever do Estado com a educação será efetivado mediante a garantia de: I - educação básica obrigatória e gratuita dos 4 (quatro) aos 17 (dezessete) anos de idade, assegurada inclusive sua oferta gratuita para todos os que a ela não tiveram acesso na idade própria [...]" (Brasil, 1988, Art. 208).

A constituição brasileira, em seu texto original, determinava que o ensino fundamental (etapa da educação básica) era de caráter obrigatório e gratuito, e deveria contemplar aquelas pessoas que não o concluíram em idade própria (Brasil, 1988). Posteriormente, a Emenda Constitucional no 14/1996 (Brasil, 1996) reiterou a oferta gratuita e obrigatória do ensino fundamental, determinando a gratuidade àqueles que não o concluíram em idade escolar. O texto em vigor, resultante da Emenda Constitucional no 59/2009 (Brasil, 2009) vinculou a obrigatoriedade e a gratuidade da educação básica à idade - como ocorre no caso argentino. A Lei de

3 Os anos de duração da escolaridade primária são definidos por cada província, conforme determinado pelo artigo $5^{\circ}$ da Constituição Nacional Argentina (Argentina, 1994). 
Diretrizes e Bases da Educação Nacional (LDBEN), na seção intitulada "Do Direito à Educação e do Dever de Educar", determina que: "Art. $4^{\circ} \mathrm{O}$ dever do Estado com educação escolar pública será efetivado mediante a garantia de: I - educação básica obrigatória e gratuita dos 4 (quatro) aos 17 (dezessete) anos de idade, organizada da seguinte forma: a) pré-escola; b) ensino fundamental; c) ensino médio [...]" (Brasil, 1996, Art. 40).

No Brasil, a educação básica está organizada em 03 etapas, quais sejam; 1. a Educação Infantil, atendendo a crianças de zero a cinco anos, sendo obrigatória a matrícula aos 04 anos de idade; 2. o Ensino Fundamental, com duração de nove anos de escolaridade e; 3. o Ensino Médio, organizado em três anos de escolaridade (Brasil, 1996). Para Flach (2009), a ampliação dos anos de escolaridade pode ser considerada um avanço, uma vez que a referida extensão pode significar um maior número de crianças e adolescentes na escola. Entretanto, considerando a organização da Educação Básica no país e a escolaridade obrigatória, podemos concluir que o fator idade, atribuído à obrigatoriedade, consolida-se como um problema educacional para o país, considerando os índices de distorção idade-série apresentado pelo Censo Escolar nos últimos cinco anos (Brasil, 2018).

Em relação ao Paraguai, a gratuidade e a obrigatoriedade da educação também estão regulamentadas pela constituição do país: 'La educación escolar básica es obligatoria. En las escuelas públicas tendrá carácter gratuito. El Estado fomentará la enseñanza media, técnica, agropecuaria, industrial y la superior o universitaria, así como la investigación científica y tecnológica" (Paraguai, 1992, Art. 76).

No ano de 1998, a Lei Geral de Educação determinou que a educação escolar básica deveria ser ofertada de forma gratuita, com caráter obrigatório: 'La educación escolar básica comprende nueve grados y es obligatoria. [...] La gratuidad podrá ser ampliada a otros niveles, instituciones o sujetos atendiendo a los recursos presupuestarios" (Paraguai, 1998, Art. 32).

Mais à frente, no ano de 2010, a Ley de la gratuidad de la educación inicial y media, no 4088, de 13 de setembro (Paraguai, 2010) ampliou a obrigatoriedade e a gratuidade da educação, de modo a atender às crianças de quatro anos da educación inicial e os adolescentes - de 14 a 16 anos - na educación media. 
Passando assim, a ofertar também um quantitativo de 13 anos de escolaridade obrigatória no país.

Atualmente, a educação formal no país está organizada em quatro níveis: 1. educação inicial, atendendo a crianças de zero a quatro anos; 2. educação escolar básica, com nove anos de escolaridade, de caráter obrigatório; 3. educação média, com quatro anos de escolaridade; e 4. educação superior (PARAGUAI, 1998).

Assim como nos países já apresentados, a educação no Uruguai tem seu princípio de gratuidade regulamentado pela constituição. "Declárase de utilidad social la gratuidad de la enseñanza oficial primaria, media, superior, industrial y artística y de la educación física [...]" (Uruguai, 1967, Art. 71).

A obrigatoriedade também está determinada no texto constitucional que registra "son obligatorias la enseñanza primaria y la enseñanza media, agraria o industrial. El Estado propenderá al desarrollo de la investigación científica y de la enseñanza técnica (...)" (Uruguai, 1967, Art. 70). Destacamos, contudo, que, no ano de 2009, a lei geral da educação, em consonância com a constituição do país, reitera o caráter gratuito da educação pública.

(Principios) - La educación estatal se regirá por los principios de gratuidad, de laicidad y de igualdad de oportunidades, además de los principios y fines establecidos en los títulos anteriores. Toda institución estatal dedicada a la educación deberá velar en el ámbito de su competencia por la aplicación efectiva de estos principios (Uruguai, 2009, Art.15).

(De la gratuidad) - El principio de gratuidad asegurará el cumplimiento efectivo del derecho a la educación y la universalización del acceso y permanencia de las personas en el sistema educativo (Uruguai, 2009, Art.16).

Quanto à obrigatoriedade, o texto da lei máxima da educação do país determina que "(...) Es obligatoria la educación inicial para los niños y niñas de cuatro y cinco años de edad, la educación primaria y la educación media básica y superior" (Uruguai, 2009, Art. 7). Buscando facilitar a compreensão dos anos associados à obrigatoriedade, faz-se necessário apontar que a estrutura da educação formal está organizada nos seguintes níveis: 1. educación inicial, atendendo a crianças de 3 a 5 anos; 2. educación primaria, com duração de seis anos; 3. educación media básica 
(o secundaria), com três anos de duração; 4. educación media superior (o bachillerato), com igual duração; 5 . educación terciaria, cursos técnicos universitários, educação tecnológica, formação em educação com caráter universitário e graduações; e (vi) educación de postgrado (Uruguai, 2009).

Para Fontoura (2008), a constituição do Uruguai, assim como a da Argentina, traz disposições bastante genéricas sobre o direito à educação. Como consequência, cabe às leis específicas da educação assumir o papel de especificar os elementos associados à proteção desse direito.

Como base nas constituições dos países analisados, as legislações que regulamentam a obrigatoriedade escolar nos Estados Parte do Mercosul Educacional apresentam aproximações e distanciamentos entre si. Podemos observar que a Educação Inicial não se constitui como uma etapa, com todos os seus ciclos, obrigatória em todos os países. De modo geral, a escolarização obrigatória, nessa etapa, é determinada a partir dos quatro ou cinco anos, ficando ainda, os três primeiros anos a cargo das famílias, sem se constituir como obrigatoriedade da oferta de vaga, por parte do Estado.

Para o International Standard Classification of Education ${ }^{4}$ (ISCED) a educação básica é o conjunto de ações educacionais escolarizadas, que visam a atender às necessidades básicas de aprendizagem definidas pela Declaração Mundial sobre Educação para Todos (ISCED, 2012). Nesse sentido, cada país organiza, da forma como the aprouver, esse conjunto de ações, desde que garanta as aprendizagens básicas, em consonância com a referida declaração.

De acordo com a padronização da ISCED, a educação básica compreende a educação primária - primeiro estágio da educação básica - e o primeiro nível da educação secundária - segundo estágio (ISCED, 2012). De tal modo, podemos observar que entre os Estados Parte do MECORSUL avançam, em relação à média da América Latina, no que diz respeito à abrangência da educação básica, uma vez

\footnotetext{
${ }^{4}$ O ISCED é a Classificação Mundial de Referência dos Sistemas Educacionais, amplamente utilizada, mantida e revisada periodicamente pela UIS em consulta com os Estados Membros e outras organizações internacionais e regionais.
} 
que a escolaridade obrigatória se dá a partir dos quatro anos, período no qual a criança está inserida na Educação Primária/Infantil.

Destacamos o inegável avanço em relação à normatização para a escolaridade obrigatória e sua gratuidade no contexto dos países do Mercosul. Porém, considerando a ideia de que os ordenamentos normativos, por si só, não garantem a efetivação do direito à Educação (UNESCO, 2013), se faz necessário que os países assumam seu(s) compromisso(s) através de investimentos para a garantia desse direito.

A tabela 2 nos possibilita apresentar dados sobre a cobertura de matrículas na educação primária e secundária dos países analisados. A partir de dados do período entre 2015 e 2019 coletados na base Unesco Institute for Statistics (UIS) foi possível observar que a educação primária está próxima da universalização do seu atendimento nos países da região. Entretanto, no que tange à educação secundária, os dados apontam que sua cobertura precisa ser ampliada, para abarcar toda a população em idade escolar para essa etapa.

Tabela 2. Taxa de sujeitos - em idade escolar - fora da escola nos Estados Parte do Mercosul (\%) - 2017

\begin{tabular}{|c|c|c|}
\hline País & $\begin{array}{l}\text { taxa de crianças fora da } \\
\text { escola } \quad \text { educação } \\
\text { primária }\end{array}$ & $\begin{array}{l}\text { taxa de adolescentes fora } \\
\text { da escola - educação } \\
\text { secundária }\end{array}$ \\
\hline Argentina & 0,43 & 10,4 \\
\hline Brasil & 0,39 & 18,59 \\
\hline Paraguai & - & 31,63 \\
\hline Uruguai & * & 19,23 \\
\hline
\end{tabular}

Fonte: Elaboração própria com base em Unesco Institute for Statistics.

* Magnitude nula ou insuficiente

Como podemos observar, os dados relacionados à educação primária, em relação à Argentina e ao Brasil apontam para a quase universalização do atendimento dos sujeitos em idade escolar para essa etapa. O Uruguai, ao que se pode constatar, universalizou esse atendimento, uma vez que - da perspectiva estatística - seus dados relacionados à não cobertura são nulos.

Entretanto, o mesmo cenário não pode ser observado em relação à cobertura da educação secundária. Conforme evidenciado na tabela 1, a referida etapa ainda 
não cobre toda a demanda, o que se constitui como um desafio a ser superado pelos países em análise. 0 que reforça a constatação de que os ordenamentos normativos - apesar de sua fundamental importância - não são a garantia do direito à educação a todos os sujeitos em idade escolar.

\section{Conclusão}

A necessidade e existência de um direito está necessariamente atrelada ao âmbito de um sistema normativo (Bobbio, 1992), no qual "a figura do direito tem como correlato a figura da obrigação" (p. 80). Nesse sentido, o acesso aos conhecimentos social e historicamente selecionados, garantido através da permanência na escola, consolida-se com elemento fundamental para que os sujeitos possam ampliar suas possibilidades de participação e transformação social (Cury, 2007).

Observamos que os ordenamentos editados por organismos internacionais (ONU, 1948, 1959, 1966; UNESCO, 1990, 2000, 2015) se consolidaram como elementos fundamentais para a normatização da escolaridade obrigatória nos países signatários. No âmbito do Mercosul, estes documentos se somaram à compreensão de que a educação se configura como elemento chave para o desenvolvimento dos países, bem como para a integração da região.

Destacamos ainda que a presença de tais ordenamentos e orientações não são garantia para a efetividade do acesso à escolaridade obrigatória de todos aqueles que se encontram na faixa etária e/ou da etapa prevista nas legislações de cada país. A elaboração de ordenamentos normativos nacionais é parte importante no processo de garantia desse direito, entretanto ela deve ser acompanhada de políticas públicas que efetivem o acesso e que garantam a permanência dos estudantes nas escolas.

\section{Referências bibliográficas}

Alesso, S. (2016). La ley de financiamiento educativo: En la Argentina una lucha histórica. Retratos da Escola, 10 (18), 75-84. 
Argentina. (1994). Constitución Nacional da Argentina. Senado de La Nación Argentina: Buenos Aires.

Argentina (2006). Ley no 26.206, de 14 de dezembro de 2006. Ley Nacional de Educación. Senado de La Nación Argentina: Buenos Aires.

Argentina (2014). Ley no 27.045, de 3 de dezembro de 2014. Declaración como Obligatoria la educación inicial para niños/as de cuatro (4) años en el sistema educativo nacional. Argentina: Buenos Aires.

Bellei, C. (2005). The private-public school controversy: The case of Chile. In Conference on Mobilizing the Private Sector for Public Education. Disponible en https://bit.ly/2zqulmH

Bobbio, N. (1992). A Era dos direitos. Rio de Janeiro: Campus.

Brasil (1988). Constituição da República Federativa do Brasil. Brasília: Senado.

Brasil (2018). Resultados e Resumos do Censo Escolar. Disponível em https://bit.ly/2SaDgzi

CEPAL (1994). El regionalismo abierto en América Latina y el Caribe: la integración económica al servicio de la transformación productiva con equidad. Cepal.

CLADE (2014). Consulta sobre la Gratuidad de la Educación Básica: aportes a partir de estudios de caso en Colombia, Guatemala, Honduras y Paraguay. São Paulo: Clade.

CLADE (2015). Las Leyes Generales de Educación en América Latina - el derecho como proyecto político. São Paulo: Clade.

Corrêa, J. (2011). Educação comparada: um esboço para compreender as fronteiras e os limites da comparação. Visão Global, Joaçaba, 14 (2), 251-272.

Cury, C. (2002). Direito à educação: direito à igualdade, direito à diferença. Cadernos de Pesquisa (116), 245-262.

Esteban, M. (2010). Pesquisa qualitativa em educação: fundamentos e tradições. Porto Alegre: AMGH.

Fanfani, E., Meo, A. e Gunturiz, A. (2010). Estado del arte: escolaridad primaria y jornada escolar en el contexto internacional. Estudio de casos en Europa y América Latina. Buenos Aires: UNESCO.

Ferrer, J. (2002). La educación comparada actual. Barcelona: Editorial Ariel. 
Flach, S. (2009). O direito à educação e sua relação com a ampliação da escolaridade obrigatória no Brasil. Ensaio: Avaliação e Políticas Públicas em Educação, Rio de Janeiro, 17 (64), 495-520.

Fontoura, J. B. (2008). A Harmonização do Sistema de Educação no Âmbito do Mercosul. (Doctoral dissertation, Faculdade de Direito, Pontifícia Universidade Católica de Minas Gerais).

ISCED (2011). International Standard Classification of Education 2011. UNESCO Institute for Statistics Montreal, Canada.

Lüdke, M. e André, M. (2013). Pesquisa em educação: abordagens qualitativas. 2 ed. São Paulo: EPU.

MERCOSUL (1991). Tratado de Assunção. Disponível em https://bit.ly/3eY4mUe Novoa, A. (1994). História da Educação. Universidade de Lisboa, Faculdade de Psicologia e Ciências da Educação. Lisboa.

Novoa, A. (2009). Educação Comparada: possibilidades e limites. Em D. B Souza e S. A. Martínez (Org), Educação Comparada: rotas de além-mar (pp. 23-62). São Paulo: Xamã.

ONU (1948). Declaração Universal dos Direitos Humanos. ONU. Disponível em https://bit.ly/35fYAJ6

ONU (1959). Declaração universal dos direitos das crianças. Brasília: UNICEF. Disponível em https://uni.cf/35d0nhR

ONU (1966). Pacto Internacional de direitos econômicos, sociais e culturais. Onu.

Disponível em https://bit.ly/3cWBKJb

Paraguai (1992). Constitución de la República de Paraguay. Assunción.

Paraguai (2010). Lei no 4088, de setembro. Ley de la gratuidad de la educación inicial y media. Assunción.

Piovesan, F. (2004). Direitos sociais, econômicos e culturais e direitos civis e políticos. Revista Internacional de Direitos Humanos, São Paulo, 1 (1), 20-47.

Rabelo, J., Segundo, M. e Jimenez, S. (2009). Educação para todos e reprodução do capital. Revista Trabalho Necessário, 7(9). 
Souza, K. R. (2017). Direito à educação nos Países Membros do Mercosul: um estudo comparado. (Doctoral dissertation) Faculdade de Ciências e Letras da Universidade Estadual Paulista.

Trojan, R. M. (2009). Políticas educacionais na América Latina: tendências em curso. Revista Iberoamericana de Educación, 51(1), 1-12.

UNESCO (2015). Declaração do Fórum Mundial de Educação. UNESCO. Disponível em https://bit.ly/2S9GJhm

UNESCO (1990). Declaração mundial sobre educação para todos e plano de ação para satisfazer as necessidades básicas de aprendizagem. Brasília: Unesco. Disponível em https://bit.ly/2zCQlet

UNESCO (2000). Declaração de Dakar: Educação para todos. Unesco. Disponível em https://uni.cf/2y47X27

UNESCO (2013). Situación Educativa de América Latina y el Caribe. Santiago: Ediciones del Imbunche.

Uruguai (1967). Constituicion de La Republica. Montividéu.

Uruguai (2009). Ley n. 18.437 del 16 enero 2009. Ley General de Educación. Montividéu.

Ventura, D. e Seitenfus, R. (1995). O MERCOSUL em movimento. Livraria do Advogado Editora: Rio Grande do Sul. 